\title{
O REINADO DE D. MANUEL E AS ORDENAÇÕES MANUELINAS
}

\author{
Luiz Carlos de Azevedo \\ Professor Associado do Departamento de Direito Processual da \\ Faculdade de Direito da Universidade de São Paulo \\ Desembargador aposentado do Tribunal de Justiça de São Paulo
}

Resumo:

No ensejo das comemorações dos quinhentos anos da descoberta do Brasil, importa considerar o seu primeiro governante, D. Manuel I, e a legislação que leva o seu nome. Colocam-se em relevo aspectos mais importantes de seu reinado, no âmbito da política interna e externa, bem como a vivência sócio-cultural contemporânea ao século XVI. Segue o exame das inovações, correções e acréscimos ocorridos na legislação, com a edição das Ordenações Manuelinas; entre outros, a aplicação do Direito subsidiário, a descrição das atribuições e encargos dos funcionários da Coroa, o Direito Processual, o valor dos assentos na interpretação autêntica da lei. Conclui-se, acentuando a importância da História do Direito, como fator de conhecimento da origem e desenvolvimento das instituições e do alcance que estas ainda possuem no contexto do ordenamento jurídico vigente.

\begin{abstract}
:
In the opportunity of the commemorations of the five hundred years of the discovery of Brazil, it matters to consider its first ruler, D. Manuel I, and the legislation that takes his name. The more important aspects of his reign are studied in the ambit of internal and external politics, as well as the contemporary sociocultural existence in the XVI century. Continuing on his study, he examines the innovations, corrections and increments happened in the legislation with "Ordenações Manuelinas" edition; among others, the application of the subsidiary right, the description of the attributions and responsibilities of the Crown's employees, the Procedural Law, the value of the "assentos" in the authentic interpretation of the law. It is ended accentuating the importance of the History of the Law, as factor of knowledge of the origin and development of the institutions and of the reach that these still possess in the context of the effective juridical system.
\end{abstract}

Unitermos: D. Manuel: Reinado; estilo; cultura; política interna e externa. 
Sumário:

1. Introdução; 2. D. Manuel I; 3. O século XVI; 4. O Reinado de D. Manuel: política interna e externa; cultura; estilo Manuelino; 5. O Direito: as Ordenações Manuelinas; 6. Os cinco livros das Ordenações Manuelinas; 7. Conclusão.

\section{Introdução}

Três foram os motivos que nos levaram à escolha do tema para a aula a ser proferida nesta manhã de agosto de 1999.

Em primeiro lugar, situa-se ele na parte do programa que cuida da História do Direito brasileiro e do Direito luso-brasileiro, por força da ascendência que os congrega: diz, assim, mais de perto com as nossas origens e instituições.

Além disso, pela proximidade com que nos encontramos com as efemérides que marcam a passagem dos cinco séculos da descoberta do Brasil, oferece-se pertinente a preferência, pois tem a ver com um dos momentos culminantes da história de Portugal e com o ponto de partida da história de nossa Pátria.

E, em terceiro lugar, porque foi D. Manuel, em realidade, o nosso primeiro governante: ademais, durante o seu reinado, promulgaram-se as Ordenações que levam o seu nome, certamente o primeiro corpo legislativo que aqui conheceu efetiva vigência; com efeito, nas duas décadas que o antecedeu, as Afonsinas tiveram minima ou nenhuma repercussão na terra de Santa Cruz, pois a política de assentamento e colonização só se iniciaria anos após·a descoberta, dado que o interesse maior da metrópole dirigia-se para o comércio com o Oriente e com as Índias. Por outro lado, as Ordenações Manuelinas, embora revogadas pelas Filipinas, em 1603, acabaram perdurando no tempo, pois grande parte de seu conteúdo passou à legislação subseqüente; assim, inúmeras de suas disposições continuaram em vigor, resistindo mesmo após a Independência do Brasil ao segundo Império, e até à República, quando, finalmente, viu-se promulgado o Código Civil (1917). 


\section{D. Manuel I}

Diz-se de D. Manuel que o nomearam venturoso; ou ainda felicíssimo, segundo as palavras de Damião de Góis; isto porque, sob sua égide desencadearamse as descobertas e o alargamento desmesurado do Império Ultramarino, desde as Índias, tão cobiçadas por suas riquezas e especiarias, até o Labrador e a Terra Nova, no outro extremo do mundo; desde o interior das Áfricas e o contato com o legendário Preste João, até os confins do Oriente e à China, quando os ousados navegadores desembarcaram em Cantão. Bem lhe ajustavam, pois, os títulos a que se refere o prólogo da compilação, considerando-o, por graças de Deus, rei de Portugal, dos Algarves, daquem e d'além-mar, senhor da Guiné, e da Conquista e Navegação e Comércio da Etiópia, Pérsia, Arábia e Índia; títulos sobejamente verdadeiros e que falsos não soavam, como assim pareceriam aos seus sucessores, por se perder no curso do tempo a maior parte de tantos domínios.

Mas sua ventura não estava restrita ao périplo dos descobrimentos, podendo ecoar em outro sítio, isto é, na fortuna da sucessão, pois D. Manuel muito longe se encontrava na descendência, para haver lugar ao título; e, não-obstante, às suas mãos acabaria ele chegando: embora bisneto de D. João I, fundador da dinastia de Aviz, neto de D. Duarte, sobrinho de D. Afonso V e primo irmão de D. João II, muitos lhe antecediam na real estirpe; mas o destino os foi afastando do trono, tanto que o infante Afonso, filho do príncipe perfeito, morre em inesperado acidente; 0 próprio rei pouco dura, definhando em dor que lhe antecipa a morte; na seqüência, os filhos de D. Fernando, mais velhos do que D. Manuel, vão gradativamente se extinguindo: dos irmãos, D. João morre moço, D. Diogo acaba assassinado, D. Dinis, D. Duarte e D. Simão igualmente não sobrevivem. E D. Jorge, filho bastardo de D. João II, é descartado por influência da rainha D. Leonor, a qual prefere, por certo, que o irmão mais jovem assuma o reino.

Daí lhe sobrarem o cetro e bem assim as façanhas que haveria de empreender, como senhor deste poderoso império que estava por formar.

\section{O século XVI}

Mais venturoso seria, ainda, pela época em que lhe foi dado viver e reinar: reabilita-se o pensamento pelo retorno à antigüidade clássica, conhece-se enorme impulso nas letras e nas artes, reaviva-se o humanismo, opera-se a 
renovação da escolástica, primeiro com Vitória, a seguir, com Suarez e De Soto. Desenvolve-se o comércio, difunde-se o saber pela descoberta da imprensa, deslumbra-se o velho mundo com o encantamento proporcionado por um mundo novo que a todos seduz e empolga.

Portugal coloca-se no entrechoque deste impacto: e se demora, talvez, em aceitar as inovações, carregado que ainda está na mundividência dos senhorios, antecipa-se em afrontar os dogmas da inabitalidade das zonas tórridas, do abismo dos oceanos, da inexistência de outros seres ou dos antípodas, por força da aventura que comanda; e o romance desta empresa será descrito tanto pela epopéia camoniana quanto pela peregrinação de Fernão Mendes Pinto: são heróis, reis e santos, mas são também os representantes da arraia-miúda, o povo que se lança ao deslumbramento e fascínio do ignorado e que se envolve neste contato entre duas civilizações: entre o ontem e o hoje, enfim.

4. O Reinado de D. Manuel: política interna e externa; cultura; estilo Manuelino

Sobre D. Manuel e seu reinado, sobressaem, nas fontes, a obra do humanista Damião de Góis, "Crônica do felicíssimo rei D. Manuel" de 1566; a par dela, De rebus Emmanuelis gestis" de autoria do bispo de Silves, Jerônimo Osório, outro renomado cultor das letras do século XVI (1571). E, ainda, a prefação da edição das Manuelinas, publicada pela Real Imprensa da Universidade de Coimbra, em 1797 cujo autor foi Francisco Xavier de Oliveira Mattos. E é Damião de Góis quem afirma ter sido o monarca "homem de muito negócio e muito contínuo no despacho das coisas que por sua mão passavam" Sem pretender acompanhar em tudo os elogios do cronista, e atendendo, como outros, que seu reinado conheceu tanto luzes quanto sombras, é de afirmar que D. Manuel foi político prudente e equilibrado, tendo levado em conta sempre como propósito o resguardo dos interesses da nação; para isso, deu todo empenho em manter a marcha ascendente que o fortaleceria no governo, buscando a centralização da administração pública, procedendo a reforma dos forais, atualizando os encargos tributários, tendendo francamente ao absolutismo, institucionalizando o Estado burocrático e mercantilista.

Em matéria de política externa, houve-se com igual habilidade, preferindo manter-se neutro nos vários conflitos que se sucediam à sua volta; e em seus três casamentos, nos quais almejara uma nunca alcançada hegemonia ibérica, 
soube, pelo menos, dignificar a Coroa portuguesa frente aos demais reinos, estabelecendo uniões com rainhas de influência e importância no contexto das monarquias européias. Por outro lado, redobrou-se o esforço no sentido de dar expansão à política ultramarina.

No campo sócio-cultural, reformam-se os estudos gerais da Universidade, dá-se particular incentivo à literatura e às artes: na transição entre o mundo feudal e o classicismo, e antecedendo a Sá de Miranda, Gil Vicente traz à Corte, sem temor a represália, suas mordazes peças teatrais, enquanto Francisco Henriques, Álvaro Peres e Jorge Afonso sucedem na pintura ao gênio de Nuno Gonçalves e aos seus célebres painéis de S. Vicente de Fora.

O estilo manuelino, de formas sólidas, robustas, decorativas, em toques orientais, simbólicos, retrata as inquietudes espirituais desse período, no qual sobreleva um modo peculiar de vida, um sentimento nacional, aventureiro, mítico; é o que nos contam as pedras dos Jerônimos e mais, ainda, os contornos da famosa janela situada no pátio interno da Casa do Capítulo do Convento de Cristo, na templária cidade de Tomar.

\section{O Direito: as Ordenações Manuelinas}

Em seus respectivos reinados, os soberanos haviam cuidado de determinar a compilação das leis de caráter geral, para conhecimento de seus súditos, tarefa que só se ultimou ao tempo de $\mathrm{D}$. Afonso $\mathrm{V}$. em meados do século $\mathrm{XV}$

Desde então, até o período em que D. Manuel assumiu o trono, a legislação extravagante engrossara, exigindo a necessidade de se promulgar novo édito, que àquele primeiro substituísse. Por outro lado, era preciso atualizar e dar correta interpretação aos textos legais, ainda vinculados a um passado que a renovação das idéias exigia.

Ademais, a possibilidade de se imprimir e divulgar a obra e, ainda assim, a oportunidade de acrescentar a seus muitos feitos a memória das novas ordenações levaram D. Manoel a encomendar a empresa a seus letrados: por carta régia de 9 de fevereiro de 1506, nomeia o chanceler Ruy Boto, o licenciado Ruy da Grã e o bacharel João Cotrim para esse fim. Mais tarde, igualmente seriam colaboradores João de Faria, Pedro Jorge e Cristovão Esteves. 
Uma primeira impressão, ocorrida em 1514, foi substituída por outra, definitiva, datada de 1521, já às vésperas da morte do monarca; ao editá-la, pretenderam este e seus legisladores fazer uma nova compilação, tirando tudo de sobejo e supérfluo e emadendo no minguado, isto é, acrescentando o que faltava, suprindo defeitos, concordando as contrariedades e declarando no sentido de por às claras, o que estava escuro ou difícil.

Maior alteração se observa no estilo, passando ao decretório: não mais, e a não ser excepcionalmente, uma repetitiva coleção de disposições; e não mais a menção dos reis que as editaram: procura-se dar ao conteúdo a feição de corpo legislativo. Mantém-se, todavia, a distribuição da matéria em cinco livros, e estes em títulos e parágrafos.

A influência do Direito Romano Canônico subsiste, bem como a vigência subsidiária daquele, embora já se justifique a guarda das leis imperiais somente quando fundadas na boa e natural razão, (O.M. II, 5, pr) longínquo prenúncio da lei que mais tarde por tal nome se identificaria.

6. Os cinco livros das Ordenações Manuelinas

Sem pretender ir além da exemplificação, cumpre abordar algumas destas alterações, supressões e acrescentamentos que nos ditos livros se contêm:

a. O primeiro livro cuida dos regimentos e dos cargos e atribuições das pessoas destinadas à administração judiciária, ali se incluindo, entre muitos, chanceleresmor, desembargadores, corregedores, ouvidores, e também meirinhos, porteiros, carcereiros; mais adiante, trata da administração em geral: vereadores, almotacés, alcaides, tabeliães. Enfim toda a máquina administrativa e burocrática do Estado.

Sobre os inquiridores, referidos apenas em dois parágrafos do título 41 das Afonsinas, há agora cuidadoso tratamento, no qual se observa o propósito da apuração da verdade dentro da correção e imparcialidade, chegando o texto legal a minuciosos detalhes, como, por exemplo, que o inquiridor não tome refeições com a parte, porque, "por azo de comer, poderá ser afeiçoado a ela"... (Tít. 65, § $5)$.

O título 73, igualmente novo, reconhecendo a responsabilidade dos cargos, prescreve que só poderão servir à Justiça, Fazenda ou governança das cidades e vilas os maiores de vinte e cinco anos. 
Sobre os quadrilheiros, "para que melhor saibam prender os malfeitores, evitando os malefícios que estes causam" há toda uma regra de conduta e instruções, distribuída em treze extensos parágrafos (Tít. 54). Como se vê, há todo um cuidado para com a administração no sentido de que esta não falte; e quando presente, bem saiba agir.

b. No segundo livro, que trata dos privilégios da Igreja e pessoas eclesiásticas, direitos e bens da Coroa e da forma de sua arrecadação, além de outras matérias, há que se ressaltar, entre outras passagens, que toda a legislação especial, relativa aos judeus e mouros (títulos 66 até 121), constante das Afonsinas, ficou reduzida a apenas dois títulos (41 e 42), repetindo o primeiro a lei datada do final do século, a qual determinara expulsar do reino aqueles que não quisessem se batizar, convertendo-se à fé cristã. Mais tolerante para com as minorias do que o seu sucessor, que irá estabelecer a inquisição em Portugal, D. Manuel, neste passo, houve por ceder aos apelos dos reis católicos, mesmo porque havia se casado com Isabel, filha destes e herdeira presuntiva de Leão, Castela e Aragão, podendo deste enlace resultar a tão desejada unificação dos reinos ibéricos (Lei de 5/XII/1496).

No título 45 incorpora-se à compilação a reforma que havia sido efetuada nos forais; na verdade, porém, e a esse tempo, haviam eles perdido o seu sentido político, mais se assemelhando, assim, a regimentos de natureza tributária e aduaneira. É interessante observar que tanto nas Manuelinas, quanto nas Filipinas, que se lhas seguirão, neste capítulo o estilo difere do decretório, vindo na primeira pessoa do plural: "mandamos fazer os ditos forais e mandamos aqui incorporar e é o seguinte de verbo a verbo"; seu neto, Filipe II de Espanha e que seria o primeiro de Portugal, repete: ... "antes que D. Manoel, de gloriosa memória, meu avô, mandasse fazer os forais ...

$\mathrm{Na}$ verdade, de longa data estes diplomas já existiam, pelo que não haviam sido "feitos" por D. Manuel: este reorganizara-os, dando-lhes outra dimensão, assim agindo com o intuito de centralizar os poderes junto à Coroa. Aliás, este cuidado aparece amiúde em outras passagens: aqueles atos mais importantes que haviam de passar pelo crivo real, cujo efeito durasse mais de ano, não seriam determinados por alvarás, mas por cartas patentes, sempre devendo figurar no começo o nome de D. Manuel. A não ser assim, "nenhuns seriam" (Tít. 20, § 5). 
No título 17 vem transcrita a Lei Mental, que não-constara das Afonsinas, provavelmente por instância dos ricos-homens e ricas-donas, que não apreciariam, por certo, a maneira ali disposta no tocante à sucessão das terras, quando não houvesse varão para herdar, pois em tal caso, retornavam elas à Coroa do reino ...

Também aqui se refere a lei a "D. Duarte, meu avô ..." sendo mais uma exceção ao estilo dos decretos, adotado em caráter geral nas Manuelinas.

Quanto ao Direito subsidiário, diferindo em parte do texto afonsino (Liv. II, Tít. 9), as Ordenações Manuelinas estabelecem que quando o caso não for determinado por lei, estilo ou costume do reino, seja julgado pelos santos cânones, sendo matéria que traga pecado; se não, pelas leis imperiais, pelo Direito Romano, posto que os sacros cânones digam o contrário. E mesmo aquele, somente se guardara pela boa razão em que se fundar. A seguir, aplicamse as glosas de Acursio e a opinião de Bártolo, desde que não contrariem a comum opinião dos doutores (Liv. II, Tít. 5).

c. O Livro III contempla o processo civil: embora atualizado e reformado em várias passagens, não se isenta de excessivo formalismo, circunstância que proporcionará subseqüente revisão legislativa já sob o reinado de D. João III (carta de 5 de julho de 1526).

$\mathrm{Na}$ verdade, imperfeições no trato da matéria, rebuscamento do estilo, lacunas aqui, repetições acolá, não permitiram fornecer à ordem do Juízo estabelecida no ordenamento manuelino a simplicidade e brevidade que dela se esperava.

No entanto, empenhou-se o legislador nesse propósito, seja por manter e até ampliar o rol das causas submetidas ao procedimento sumário (Tít. 36), seja por introduzir a ação de assinação de dez dias, ou ação decendiária, pela qual o credor pretendia haver do devedor quantia ou coisa a que este se obrigara, conforme provava escritura ou alvará feito e assinado (Tít. 16). Precursora da atual ação monitória (art. 1.102, "a" "b" e "c" do Código de Processo Civil) trazia salutar medida ao determinar que o vencido pagasse em dobro o principal, revertida esta última parte às obras pias.

Outra nota positiva é a clareza com que define a contagem dos prazos: para o termo inicial, não se entenderá o dia em que assinado; mas o último dia em que se acabou o termo será compreendido, salvo se feriado, quando se 
prorrogará até o dia seguinte (Tít. 12). É o que dispõe o atual Código de Processo Civil no art. 184 e seus parágrafos.

Integram-se ao processo várias figuras de intervenção de terceiro, desconhecidas nos éditos anteriores: assim, o opoente, o assistente (Tít. 15, § 14) o terceiro embargante (Tít. 71, § 32).

Embora já existisse nas Afonsinas o estormento do agravo, meio pelo qual se pedia, por escrito, a correção do gravame causado por sentença interlocutória simples, contra a qual não era permitido apelar, o agravo, com a característica de recurso próprio contra essa sentença, surgirá somente nas Manuelinas, v.g., Tít. 77. §§ 1 e 17

Finalmente, foi nas Manuelinas que se firmou e se ampliou o conceito do "prior tempore potior iure" (Tít. 74): "o credor, que primeiro fizer execução" e per ella penhora" nos bens do devedor, "precederá os outros, posto que sejam primeiros em tempo“; leis posteriores, já no século XVIII, iriam estabelecer a "par conditio creditorum' mas, com o advento do Código de Processo Civil de 1973, retornou-se àquele sistema tradicional de precedência da primeira penhora (art. 612).

d. Chega-se ao Livro IV. que trata, na maior parte, do Direito Civil, estendendo-se na parte relativa aos contratos e ao Direito Sucessório, pelo que guarda a marca do Direito Comum e as origens Justinianéias. O Título 82 traz matéria nova, esclarecendo que, "para evitar enganos e demandas" (...) "pessoa alguma não faça venda alguma, nem troca que desigual seja, a seu filho, neto ou outro descendente, sem consentimento dos outros filhos, netos ou descendentes" ... disposição que passaria às Filipinas, Tít. 12, chegando ao nosso Código Civil, arts. 1.132 e 1.164, II. Anote-se, contudo, que a recusa ao consentimento, na legislação reinol, podia ser suprida pela licença real.

No sentido de resguardar a dignidade do cargo para o qual haviam sido investidos, corregedores, juizes e outros oficiais não podiam adquirir bens de raiz nas localidades onde exerciam seus ofícios, nem arrendar coisa alguma aos rendeiros do rei (Títs. 38 e 39). E para que nenhuma pessoa, de qualquer estado ou condição, não faça contrato simulado, prescreve-se a perda do bem para as partes que assim agirem, a par da pena de degredo para a ilha de São Tomé ou para os lugares da África, substituído o primeiro destino para o Brasil 
na Ordenação seguinte (O.M. Tít. 15; O.F. Tít. 71). Não-obstante, embora se considere este contrato "nenhum" por direito, se o faltoso, antes da acusação, comunica o defeito à Justiça, "não incorrerá em pena alguma" e será perdoado.

O Direito medieval da avoenga, pelo qual os bens imóveis herdados dos pais ou avós submetiam-se a regime específico de transmissão, dando-se preferência aos parentes, é definitivamente abolido nas Ordenações Manuelinas, Tít. 25. As Afonsinas já haviam "corrigido" antiga lei a esse respeito, oriunda de D. Afonso II, (O.A. Liv. IV. Tít. 37. § 2) por entender que ela, a par de não ter sido usada e nem guardada, contrariava o Direito Comum; mas mantivera o título 38 , sobre a dita lei, enquanto que a legislação de D. Manuel, de modo incisivo e claro, além de suprimir todo este último título, dispõe que "cada um possa vender seu herdamento e coisas que tiver e não seja constrangido de as vender contra a vontade".

e. Não há como pintar com cores amenas o atribulado caminho para a outorga das liberdades: naquele século XVI, e por longo tempo ainda, ficariam os réus à mercê das disparidades de tratamento, segundo suas condições e estado; e à mercê da discricionaridade e arbitrariedade dos juízes, que não lhes davam conta das razões porque haviam sido condenados; e se sujeitavam às violências do sistema, açoites, mutilações, degredo para os limites mais distantes do reino, quando não a pena de morte "por ello" Este era o trato, do qual não se eximiu a legislação penal disposta no Livro V. farta e severa na aplicação de sanções dessa natureza, conforme ocorria, aliás, e na mesma intensidade, nos demais corpos legislativos das nações européias.

Sem que se desvaneça esta impressão negativa, que passaria à história como exemplo do desprezo que se votava à liberdade individual, cabe apontar a existência, na legislação manuelina, de dois institutos, ambos ascendendo à remota origem, dado que provêm dos mais antigos forais: são as scguranças reais que se solicitam à Justiça, não por criminosos, mas por inocentes "que temem com justa causa ser inquietados por outros" (Forais de Fresno. $1.152 \mathrm{~m}$ Urros, $1.182 \mathrm{~m}$ Freixel, 1.195, Touro, 1.220, Ordenações Afonsinas, Liv. V 122 , Manuelinas, V 50 e Filipinas, V. 128). E, a par destas, as cartas de seguro, tão antigas quanto as primeiras, e que se oficializaram nas Cortes d'Elvas de 1361; consistiam no decreto pelo qual o juiz concedia ao réu pronunciado para captura a faculdade de comparecer em juízo e, sob certas condições, regressar solto do 
crime de que era acusado. Sob esta promessa judicial, o réu permanecia em liberdade, até que se concluísse a causa (Cortes d'Elvas, 1361, art. 84; O.A. Liv. V Tít. 57; O.M. V. Tít. 49; O.F V Tít. 129).

Importante matéria consta do Título 58, quando ali se estabelecem as cominações a que se sujeitavam desembargadores, corregedores, ouvidores e julgadores que não-cumprissem e guardassem as ordenações: anulação do julgado, suspensão do ofício, pagamento de multa às partes no valor de vinte cruzados; era uma forma de coibir abusos, peitas ou erronias dos magistrados, nem sempre ciosos de seus deveres e responsabilidades.

Além disto, este mesmo título cuida da interpretação autêntica da lei, transcrevendo e ampliando disciplina colocada, pela primeira vez, em alvará datado de 1518: este privilégio do rei é transferido para a Casa da Suplicação, de tal forma que, quando os desembargadores tiverem dúvida no entendimento de alguma ordenação, devem levá-la ao regedor, o qual, na Mesa grande, e com os desembargadores que bem lhe parecer, a determinará; e segundo o que foi ali determinado, se "poerá a sentença" (O.M. Liv. V. Tít. 58, 1) que se registrará em livro próprio.

Desta prática surgiram os assentos, cujo valor normativo se identificava com o das próprias leis interpretadas; com o tempo, porém, também as Relações do Porto, Goa e Rio de Janeiro passaram a ditar assentos, dando ensejo às várias exegeses, circunstância que levou a Lei da Boa Razão a restringir este direito somente àquele primeiro tribunal superior. Por outro lado, $\mathrm{e}$ a partir daí, o assento da Casa da Suplicação tornou-se norma cogente, elevandose à categoria de fonte imediata de direito (Lei de 18 de agosto de $1769, \S 8^{\circ}$ ).

Com a criação da Casa de Suplicação do Brasil, em maio de 1808 , este tribunal adquiriu competência para proferir assentos no campo de sua jurisdição, assim agindo até sua transformação em Supremo Tribunal de Justiça, ocorrida após a independência.

Quando se cuida, agora, da introdução da súmula vinculante em nosso Direito, apresentam-se de indiscutível valor os subsídios históricos aqui anotados a respeito do alcance e extensão que se deu, àquele tempo, aos assentos emanados dos tribunais competentes para o julgamento de recursos. 
7. Conclusão.

Mesmo após a emancipação política, continuaram em vigor no Brasil as Ordenações do Reino bem como as numerosas leis extravagantes editadas no interregno, de modo que o Direito que aqui se aplicava, continuou recebendo a influência de um atávico condicionamento histórico, já que adjungido à tradição jurídica lusitana e, por conseqüência, aos princípios do Direito Comum.

E se, com o correr dos anos, o nosso Direito não se mostrou infenso e nem afastou a contribuição de novos conceitos, também não-destruiu, pelo contrário, consolidou a obra formada no passado, adaptando-a às necessidades do meio e às evoluções próprias do ambiente social. Anos atrás, os professores Paulo Merea e Braga da Cruz acentuavam que este lavor não é resultado tão-só das velhas ordenações e dos seus preceitos, muitos deles já ultrapassados e obsoletos: veio expurgado, para que lenta e sabiamente se erguesse uma estrutura capaz de atender aos anseios da nação nova, constituindo o produto da colaboração harmoniosa dos órgãos legislativos, da doutrina e da jurisprudência.

Até o Direito Processual, sempre solerte em acompanhar este constante evoluir, deixou anotado na Exposição de Motivos do Código vigente que esse estatuto, embora moldado nos modernos princípios da técnica legislativa, não desatendeu aos velhos princípios fundamentais que o instruem e sustentam; assim, conservação e inovação se harmonizaram, isto porque o reformador não deve se esquecer de que por mais antigo que seja o edifício, sempre dele se obtém, quando demolido, materiais úteis às construções futuras.

Pode-se concluir, então, afirmando que o passado, visto sob tal enfoque, passado na verdade não é, pois continua presente nas mais variadas manifestações do agir humano; por outro lado, aquilo que se diz inédito, nem sempre em verdade o é, quando aparenta.

Este o sentido que se há de reconhecer ao estudo da história e da História do Direito: deste empenho, estar-se-á compreendendo melhor a origem, formação e desenvolvimento do instituto ou dos institutos examinados; estar-se-á conhecendo o alcance da contribuição que deram para a composição de nosso ordenamento jurídico; e se estará visualizando a maneira como eles se projetaram até a atualidade e de que modo continuam repercutindo na estrutura da legislação vigente.

São Paulo, agosto de 1999. 
Bibliografia

AZEveDO, Luiz Carlos. Carta de Seguro, "habeas corpus" lusitano, in Ciência Penal, ano III, v. 3, 1976, p. 133.

BRAGA DA CRUZ, Guilherme. Formação histórica do moderno Direito Privado português e brasileiro, in Revista da Faculdade de Direito da Universidade de São Paulo, v. 50, 1955, pp. 65 e ss.

O Direito Subsidiário na História do Direito Português, Coimbra, 1975, Faculdade de Letras da Universidade de Coimbra.

COELHO DA ROCHA, M. A. Ensaio sobre a História do Governo e da Legislação de Portugal, Coimbra, 1872, Real Imprensa da Universidade.

COSTA, Mario Júlio de Almeida. História do Direito Português, Coimbra, 1966, Almedina.

Verbete "Ordenações" in Dicionário da História de Portugal, Joel Serrão, Iniciativas Editoriais, Lisboa, 1971.

FERREIRA, Maria Emília Cordeiro. Verbete, "Manuel I" in Dicionário da História de Portugal, Joel Serrão, Iniciativas Editoriais, Lisboa, 1971.

GÓIS, Damião de. Crónica de felicíssimo Rei D. Manuel, Coimbra, por ordem da Universidade, 1949, edição conforme a primeira, de 1566 (Acta Universitatis Conimbrigenisis).

HESPANHA, Antonio Manuel. Histórias das Instituições, época medieval e moderna, Coimbra, 1982 Livraria Almedina.

MARQUES, A. H. de Oliveira. História de Portugal, Lisboa, 1975, Palas Editores, V. I.

MATTOSO, José. História de Portugal, s. local imp., s. data, Editorial Estampa, vs. 1 e 2 .

Identificação de um País (ensaio sobre as origens de Portugal), Lisboa, 1995, Ed. Estampa, vs. I (oposição) e II (composição).

ORDENAÇÕES AFONSINAS, Lisboa, Calouste Gulbenkian, edição "fac-simile" da edição de 1792, feita na Real Imprensa da Universidade de Coimbra.

ORDENAÇÕES FILIPINAS, Lisboa, Calouste Gulbenkian, reprodução "fac-simile" da edição brasileira de Cândido Mendes de Almeida (14 ed.), Rio de Janeiro, 1870, Tipografia do Instituto Filomático, (segundo a $1^{\text {a }}$, de 1603 e a nova, de 1824). 
ORDENAÇÕES MANUELINAS, Lisboa, Fundação Calouste Gulbenkian, 1984, edição "fac-simile" da edição feita na Real Imprensa da Universidade de Coimbra, no ano de 1797 No livro I, vem a "Prefação" de Francisco Xavier de Oliveira Mattos.

OSÓRIO, D. Jeronimo. De rebus emmanuelis gestis.

SILVA, Nuno Espinosa Gomes da. História do Direito Português, Lisboa, 1985, Fundação Calouste Gulbenkian.

VELASCO, Ignacio Poveda. Ordenações do Reino de Portugal, in Revista da Faculdade de Direito da Universidade de São Paulo, v. 89, 1994, pp. 11 e ss. 